\title{
Nuclear expression of dynamin-related protein 1 in lung adenocarcinomas
}

\author{
Yung-Yen Chiang ${ }^{1, *}$, Shu-Liang Chen ${ }^{2, *}$, Yi-Ting Hsiao ${ }^{3, *}$, Chun-Hua Huang ${ }^{3}$, Tze-Yi Lin ${ }^{4}$, \\ I-Ping Chiang ${ }^{4}$, Wen-Hu Hsu ${ }^{5,6}$ and Kuan-Chih Chow ${ }^{3}$ \\ ${ }^{1}$ Department of Dental Laboratory Technology, Central Taiwan University of Science and Technology, \\ Taichung, Taiwan; ${ }^{2}$ Feng-Yuan Hospital, Feng-Yuan, Taiwan; ${ }^{3}$ Graduate Institute of Biomedical Sciences, \\ National Chung Hsing University, Taichung, Taiwan; ${ }^{4}$ Department of Pathology, China Medical University \\ Hospital, Taichung, Taiwan; ${ }^{5}$ Institute of Clinical Medicine, National Yang-Ming University, Taipei, Taiwan \\ and ${ }^{6}$ Division of Thoracic Surgery, Department of Surgery, Taipei Veterans General Hospital, Taipei, Taiwan
}

\begin{abstract}
Dynamin-related protein 1 (DRP1), an $80 \mathrm{kDa}$ GTPase, is involved in mitochondrial fission and anticancer drugmediated cytotoxicity, which implicate an association with disease progression of cancer. In this study we investigated the prognostic value of DRP1 in lung adenocarcinomas. Using immunohistochemistry, we measured the expression of DRP1 in 227 patients with lung adenocarcinomas. Expression of DRP1 was confirmed by immunoblotting. The correlation between DRP1 expression and clinicopathological parameters was analyzed by statistical analysis. Difference of survivals between different groups was compared by a logrank test. The results showed that DRP1 expression was detected in 202 patients with lung adenocarcinomas. Among these, nuclear DRP1 (DRP1 ${ }^{\text {nuc }}$ ) was detected in 184 patients. A significant difference was found in cumulative survival between patients with high DRP1 ${ }^{\text {nuc }}$ levels and those with DRP1 ${ }^{\text {cyt }}$ levels $(P<0.001)$. In vitro, hypoxia increased DRP1 ${ }^{\text {nuc }}$ levels and cisplatin resistance. Antibodies specific to DRP1 co-precipitated a human homologue of yeast Rad23 protein A (hHR23A) and silencing of hHR23A decreased the nuclear DRP1 level and cisplatin resistance. In conclusion, DRP1 ${ }^{\text {nuc }}$ is highly expressed in lung adenocarcinomas, and correlates with poor prognosis. Nuclear DRP1 may increase drug resistance during hypoxia, and hHR23A is essential for nuclear transportation of DRP1. Our results suggest that other than the protein level alone, intracellular distribution of the protein is critical for determining the protein function in cells.
\end{abstract}

Modern Pathology (2009) 22, 1139-1150; doi:10.1038/modpathol.2009.83; published online 12 June 2009

Keywords: dynamin-related protein 1; nuclear transport; cisplatin resistance; lung adenocarcinomas; hHR23A; AMPK

Mitochondria are one of the major organelles responsible for intracellular regulation of programmed cell death. Interestingly, although three types of programmed cell death have been characterized and each has its own cellular features, ${ }^{1,2}$ dynamin-related protein 1 (DRP1) and mitochondria are involved in all three types of programmed cell death. ${ }^{2-4}$

DRP1 is an $80 \mathrm{kDa}$ GTPase belonging to the dynamin superfamily, which mediates budding and scission of a variety of vesicles and organelles inside cells. Dynamins are required for fission of

Correspondence: Professor K-C Chow, PhD, Graduate Institute of Biomedical Sciences, National Chung Hsing University, 250 Kuo-Kuang Road, Taichung 40227, Taiwan.

E-mail: kcchow@dragon.nchu.edu.tw

*These authors contributed equally to this work.

Received 12 January 2009; revised 22 April 2009; accepted 23

April 2009; published online 12 June 2009 peroxisomes and mitochondria, ${ }^{5}$ in particular, the later one at mitosis. ${ }^{6}$ It has been demonstrated that during fission DRP1 is recruited by human homologue of yeast fission protein 1 (hFis1) to a punctuate structure on mitochondrial outer membrane, thereby acting as a mechanoenzyme to mediate membrane constriction. ${ }^{7,8}$ A number of commonly used anticancer drugs, such as epipodophyllotoxins and cisplatin, accelerate organelle fission, and convincing evidence indicates that mitochondrial fragmentation is closely associated with cytotoxicity of these drugs. ${ }^{3,9,10}$ Therefore, a better understanding of DRP1 expression and activity would be useful in improving the efficacy of these chemotherapeutic agents. In addition, these drugs might prove to be valuable probes in characterizing the fundamental function and control mechanism of DRP1 and other fusion/fission-related proteins in mitochondrial fragmentation and membrane shuttling of organelles. However, DRP1 has 
not been studied in non-small-cell lung cancer, in particular, the lung adenocarcinomas, of which the incidence and mortality have increased dramatically in the past two decades. Treatment failures, which are mainly caused by DNA repair- and hypoxiaassociated drug and radiation resistance, ${ }^{11,12}$ are major reasons for the high disease-related mortality.

In this study, we used immunohistochemistry and immunoblotting to determine DRP1 expression in lung adenocarcinomas. We also evaluated the statistical correlation between the expression of DRP1 and the clinicopathological parameters of patients with lung adenocarcinomas as well as the prognostic significance of DRP1 expression in patients with lung adenocarcinomas. This study also investigated the effect of hypoxia on DRP1 expression and drug resistance in vitro.

\section{Materials and methods}

\section{Tissue Specimens and Lung Cancer Cell Lines}

We evaluated pathology specimens from 468 patients in whom non-small-cell lung cancer had been diagnosed during the period from August 1986 to November 2003. Among these patients, lung adenocarcinomas had been diagnosed in 227 patients. Stage of the disease was classified (in patients admitted after 1999) or re-classified (in patients admitted before 1999) according to the new international staging system for lung cancer. ${ }^{13}$ The medical ethics committee of the China Medical University Hospital approved the protocol, and written informed consent to donate biopsy specimens was obtained from each patient. All patients had undergone surgical resection and radical N2 lymph node dissection, followed with six cycles of cisplatin-based chemotherapy. After treatment, patients were routinely followed every 3-6 months in outpatient department. Immunohistochemical staining was carried out using a single-blinded procedure.

Seven lung cancer cell lines (H23, H226, H838, H1437, H2009, H2087 and A549) and one uterine cervical cancer line (HeLa) were used to evaluate DRP1 expression in vitro. Among those, H23, H838, H1437, H2009, H2087 and A549 are lung adenocarcinoma cells, and H226 is an epithelial type. The cell culture conditions used in this study have been described previously. ${ }^{14}$ Hypoxia was induced by incubating cultured cells with $1.0 \% \mathrm{O}_{2}$ and $5 \% \mathrm{CO}_{2}$ for more than $3 \mathrm{~h}$.

\section{Reverse Transcription-Polymerase Chain Reaction and Preparation of Monoclonal Antibodies}

Following total RNA extraction and first-strand cDNA synthesis, an aliquot of cDNA was subjected to 35 cycles of PCR to determine the integrity of $\beta$-actin mRNA. ${ }^{14}$ The cDNA used in the following reverse transcription (RT)-PCR was adjusted according to the quantity of $\beta$-actin mRNA. The primer sequences for DRP1 were 5'-AATCCTAATTCCATTATCCTCGCT-3' (nts 598621, NM_005690.2) and 5'-ACCAGTAGCATTTC TAATGGC-3' (nts 1275-1255).

The amplified products were analyzed on $1 \%$ agarose gel, and visualized by ethidium bromide staining. The DRP1 fragment was $678 \mathrm{bp}$. The cDNA was inserted into plasmid pCRII and the DNA sequence was determined by an automatic DNA sequencer (ABI PRISM; PerkinElmer Applied Biosystems, Foster City, CA, USA). The DNA sequence corresponding to the $\mathrm{N}$-terminal amino acids 48-226 was amplified by primer sequences containing EcoRI (sense) and SalI (antisense) restriction sites, respectively. The primer sequences were $5^{\prime}$-TCCGAATTCATGGACCTGCTT CCCAGAGGTACT-3' (EcoRI site is underlined) and $5^{\prime}$-TTGTCGACGTCACTAGGCATCAGTACCCGCATC-3' (Sall site is underlined).

The $534 \mathrm{bp}$ cDNA of DRP1 was cloned into the expression vector $\mathrm{pET}-32 \mathrm{~b}^{+}$(pET32 ${ }^{+}$-AIF; Promega KK, Tokyo, Japan). Bacterial colonies containing the pET32 ${ }^{+}$-DLP were selected, and induced by isopropyl- $\beta$-D-thiogalactopyranoside to mass-produce AIF. The recombinant protein was purified by a nickel-affinity column, and protein identity was determined by MALDI-TOF. Affinity-purified DRP1 fragments were used to immunize BALB/c mice, and sensitivity of antiserum $\left(\mathrm{OD}_{405}>0.6\right.$ at $1: 3000$ dilutions) was measured by enzyme-linked immunosorbent assay. Specificity of antibodies was validated when discrete bands with a molecular weight of $80 \mathrm{kDa}$ on the immunoblot of the lung cancer cell extract were detected. In some cases, protein bands $>80 \mathrm{kDa}$ appeared. ${ }^{6}$ Monoclonal antibodies were produced by a hybridoma technique, and DRP1-specific antibodies were screened by the above-mentioned methods.

\section{Immunoprecipitation, Gel Electrophoresis and Protein Analysis by MALDI-TOF}

Total cell lysate was prepared by mixing $5 \times 10^{7}$ cells per $100 \mu \mathrm{l}$ phosphate-buffered saline (PBS) with an equal volume of $2 \times \mathrm{NP}-40$ lysis buffer ( $40 \mathrm{mM}$ Tris-HCl (pH 7.6), $2 \mathrm{mM}$ EDTA, $300 \mathrm{mM}$ $\mathrm{NaCl}, 2 \% \mathrm{NP}-40$ and $2 \mathrm{mM}$ phenylmethylsulfonylfluoride (PMSF)). The Protein G Sepharose (Amersham Biosciences AB, Uppsala, Sweden) was prewashed before mixing with $500 \mu \mathrm{g}$ of total cell lysate. The reaction mixture was incubated at $4{ }^{\circ} \mathrm{C}$ for $60 \mathrm{~min}$, and then centrifuged at $800 \mathrm{~g}$ for $1 \mathrm{~min}$. The supernatant was reacted with $5 \mu \mathrm{g}$ of purified monoclonal antibodies and $20 \mu \mathrm{l}$ of fresh Protein G Sepharose at $4{ }^{\circ} \mathrm{C}$ for $18 \mathrm{~h}$. The reaction mixture was centrifuged at $800 \mathrm{~g}$ for $1 \mathrm{~min}$. Following removal of the supernatant, the precipitate was washed with $1 \times$ PBS, and dissolved in loading buffer $(50 \mathrm{mM}$ Tris 
(pH 6.8), $150 \mathrm{mM} \mathrm{NaCl}, 1 \mathrm{mM}$ disodium EDTA, $1 \mathrm{mM}$ PMSF, $10 \%$ glycerol, $5 \% \beta$-mercaptoethanol, $0.01 \%$ bromophenol blue and 1\% SDS). Eletrophoresis was carried out on two $10 \%$ polyacrylamide gels with $4.5 \%$ stacking. One gel was processed for immunoblotting, ${ }^{15}$ and the other was stained with Coomassie blue. Protein bands on the Coomassie-stained gel, which corresponded to the immunoblotting-positive bands, were extracted from the gel for identification by MALDI-TOF on a Voyager-DE Pro Biospectrometry Workstation (Applied Biosystems, Milpitas, CA, USA). Fragments of peptide fingerprints were matched with those on the SwissProt database by MS-Fit (ProteinProspector 4.0.5, The Regents of the University of California). After electrophoresis, proteins on the first gel were transferred to a nitrocellulose membrane for immunoblotting. The membrane was probed with specific antibodies. The signal was amplified by biotin-labeled goat anti-mouse IgG, and peroxidase-conjugated streptavidin. The protein was visualized by exposing the membrane to an X-Omat film (Eastman Kodak, Rochester, NY, USA) with enhanced chemiluminescent reagent (NEN, Boston, MA, USA).

\section{Fractionation of Cellular Components}

Fractionation of subcellular components was performed according to the manufacturer's instructions (Calbiochem: http://www.merckbiosciences.co.uk) with minor modifications. The cells were detached from culture plates by treating them with dissociation buffer (Sigma, St Louis, MO, USA) at $37^{\circ} \mathrm{C}$ for 2-5 min. After washing with PBS, the cells were resuspended in homogenization buffer $(10 \mathrm{mM}$ Tris-HCl (pH 7.4), $10 \mathrm{mM} \mathrm{KCl,} 1.5 \mathrm{mM} \mathrm{MgCl}_{2}$, $1 \mathrm{mM}$ Na-EDTA, $1 \mathrm{mM}$ Na-EGTA, $1 \mathrm{mM}$ dithiothreitol, $250 \mathrm{mM}$ sucrose, $0.1 \mathrm{mM}$ PMSF, leupeptin $(10 \mu \mathrm{g} / \mathrm{ml})$, aprotinin $(10 \mu \mathrm{g} / \mathrm{ml})$ and trypsin inhibitor $(10 \mu \mathrm{g} / \mathrm{ml}))$ at $4^{\circ} \mathrm{C}$ for $15 \mathrm{~min}$. After 80 strokes with a B pestle in a douncer, the unbroken cells were removed by centrifugation at $30 \mathrm{~g}$ for $5 \mathrm{~min}$. The nuclei were collected by spinning the solution at $80 \mathrm{~g}$ for $10 \mathrm{~min}$, and mitochondria were collected from the supernatant by centrifugation at $6000 \mathrm{~g}$ for $20 \mathrm{~min}$. Following centrifugation at $20000 \mathrm{~g}$ for $20 \mathrm{~min}$ to remove the insoluble residue, the final supernatant was used as the cytosolic fraction.

\section{Immunoblotting, Immunological and Immunofluorescent Staining}

The procedure for immunoblotting has been described previously. ${ }^{15}$ Briefly, proteins were separated on a $10 \%$ polyacrylamide gel with $4.5 \%$ stacking gel. After electrophoresis, proteins were transferred to a nitrocellulose membrane. The membrane was then probed with specific antibodies. The protein was visualized by exposing the membrane to an X-Omat film (Eastman Kodak) with enhanced chemiluminescent reagent (NEN). The same antibodies were used for immunohistochemistry and immunofluorescence confocal microscopy. Immunological staining was performed by an immunoperoxidase method as previously described. ${ }^{14}$ For immunofluorescence staining, MitoTracker Green FM (Molecular Probes Inc., Eugene, OR, USA) was used to label mitochondria, and nuclei were stained with $4^{\prime}$,6-diamidino-2-phenylindole (DAPI). Slides were examined under a laser scanning confocal microscope (LSM510; Zeiss, Chicago, IL, USA).

\section{Cytotoxicity Assay}

Cells were seeded at 1000, 2500 and 5000 cells per well $18 \mathrm{~h}$ before drug challenge. The cells were treated continuously with various concentrations of cisplatin (range, $1.6 \mu \mathrm{M}$ to $1.0 \mathrm{mM}$ ) for $72 \mathrm{~h}$. Following drug challenge, $10 \mu \mathrm{l}$ of WST-1 (BioVision, Mountain View, CA, USA) was added and incubation was continued for $2 \mathrm{~h}$. Percent survival of cells was quantified by comparing the number of viable cells in the treatment group with those in the control group. All procedures were performed in triplicate.

\section{Slide Evaluation}

In each pathological section, non-tumor lung tissues were served as the internal negative control. ${ }^{14}$ Slides were evaluated by two independent pathologists without clinicopathological knowledge. Strong and moderate signals were indicative of DRP1 overexpression; weak or negative signals indicated low expression of DRP1.

\section{Statistical Analysis}

The relationship between DRP1 expression and clinicopathological parameters was analyzed by $\chi^{2}-$ test or $\chi^{2}$-test for trend when a clinicopathological parameter was over two categories. Survival curves were plotted using the Kaplan-Meier estimator ${ }^{16}$ and GraphPad Prism5 statistical software (GraphPad, San Diego, CA, USA). Statistical difference in survival among different groups was compared by the log-rank test ${ }^{17}$ and log-rank test for trend. Univariate and multivariate analyses were performed using SPSS statistical software (SPSS Inc., Chicago, IL, USA). A $P$-value $<0.05$ was taken as being statistically significant.

\section{Results}

\section{Functional Characterization of Monoclonal Antibodies to DRP1}

Specificity of monoclonal antibodies was determined by an immunoblotting analysis of whole-cell 
lysate. Three protein bands of approximately $80 \mathrm{kDa}$ were detected by the antibodies (Figure 1a). Protein bands higher than $80 \mathrm{kDa}$ indicated phosphorylated DRP $1,{ }^{6}$ which were sensitive to alkaline phosphatase (Figure 1b). DRP1 level varied among cancer cells: the level was high in H838, H23, H2009 and H226 cells, and moderate in H2087, A549 and HeLa cells. H1437 cells only minimally expressed DRP1. Expression of DRP1 was confirmed by RT-PCR. Specificity of amplified cDNA fragments was verified by DNA sequencing, and DNA sequencematched DRP1 (NM_012063, www.ncbi.nlm.nih. gov/GenBank database). No polymorphism or mutation was found. It is worth noting that no significant difference was found in expression levels of DRP1 mRNA; thus, the marked variation in protein levels could be resulted from translation efficiency in different cancer cells. Protein precipitated by antibodies was characterized by MALDI-TOF. The peptide mass fingerprint matched that of DRP1: O00429, DRP1. Immunocytochemical staining showed that DRP1 was abundantly present in cancer cells (MS-Fit search, http://prospector.ucsf.edu/). The granular appearance of the subcellular structures suggested that DRP1 was present in mitochondria, nucleoli and transport vesicles, eg, peroxisomes. ${ }^{5}$ Confocal immunofluorescence images confirmed that DRP1 was located in mitochondria, nucleoli (Figure 1c1) and peroxisomes (Figure 1c2). Treatment with siRNA markedly decreased DRP1 expression (Figure 1d1), only a few residual DRP1 retained on mitochondria and mitochondria became
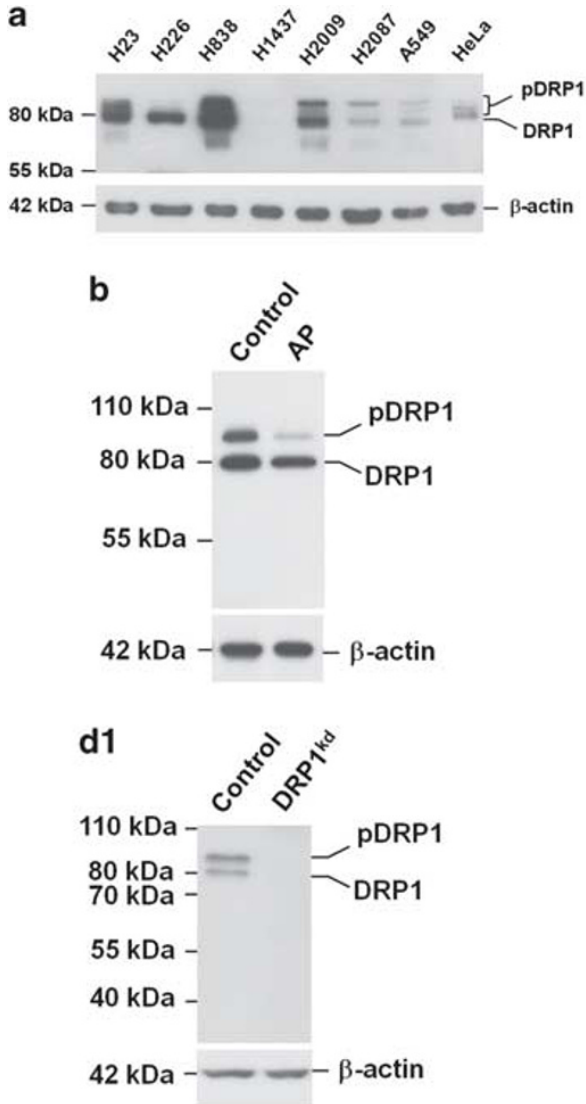

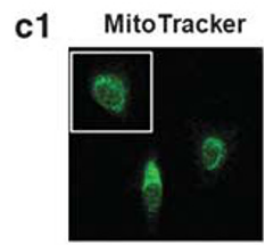

c2

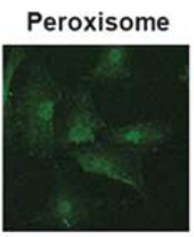

d2
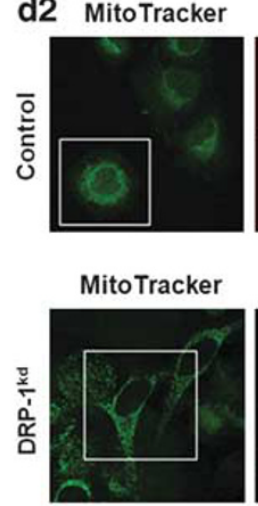

DRP1

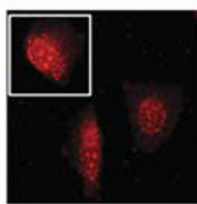

DRP1

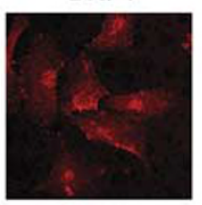

DRP1

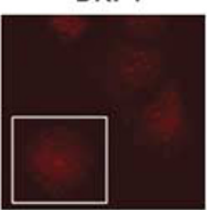

DRP1

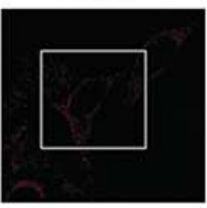

DAPI

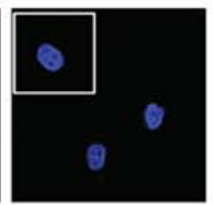

DAPI

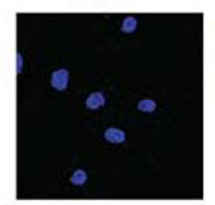

DAPI

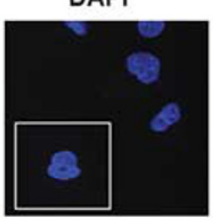

DAPI

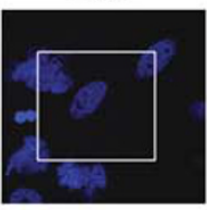

Merge

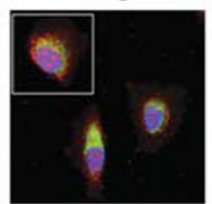

Merge

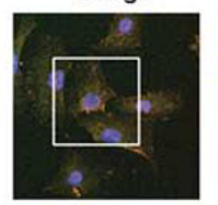

Merge

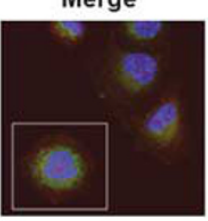

Merge

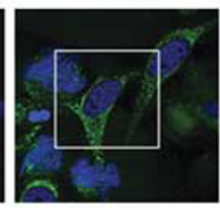

Magnification

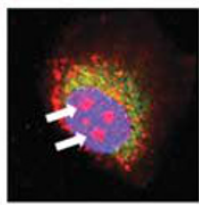

Magnification

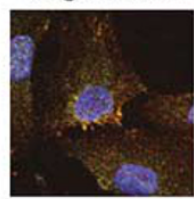

Magnification

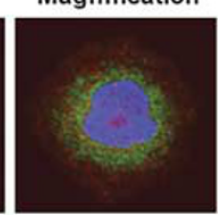

Magnification

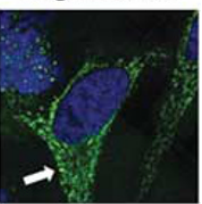

Figure 1 Characterization of monoclonal antibodies to DRP1. (a) Immunoblotting revealed that monoclonal antibodies raised against recombinant DRP1 recognized three protein bands of approximately $80 \mathrm{kDa}$. These proteins were precipitated by DRP1-specific monoclonal antibodies and Protein G Sepharose, and characterized by MALDI-TOF. The peptide mass fingerprint of the $80 \mathrm{kDa}$ protein matched that of DRP1: MS-Fit search (http://prospector.ucsf.edu/): O00429, dynamin-related protein 1. (b) The protein band (pDRP1) with a molecular weight higher than $80 \mathrm{kDa}$ (DRP1) was sensitive to alkaline phosphatase (AP). (c) Distribution of DRP1 as determined by immunofluorescence confocal microscopy. (c1) H838 cells were fed with MitoTracker Green FM (mitochondria-specific dye, green fluorescence) before stained with DRP1-specific monoclonal antibodies labeled with rhodamine (red fluorescence). In merged images, the yellow fluorescence, which was enhanced when red and green fluorescence overlapped at the same location, confirmed that DRP1 was located on mitochondria. The remaining red fluorescent specks indicated that DRP1 was also distributed in nucleoli (arrows) and other organelles. (c2) Confocal immunofluorescence cytochemistry showed that DRP1 (labeled with rhodamine, red fluorescence) was located on peroxisome (labeled with GFP, a green fluorescent protein), as the merged images (the yellow fluorescence), which was produced when red and green fluorescence overlapped at the same spot. Nuclei were stained with blue fluorescent dye 4',6-diamidino-2phenylindole (DAPI). (d) Knockdown (kd) of DRP1 expression with siRNAs (DRP1 ${ }^{\mathrm{kd}}$ ) for $96 \mathrm{~h}$ reduced the protein level of DRP1, (d1) as determined by immunoblotting analysis, and (d2) as observed by confocal fluorescence immunocytochemistry. In DRP1 ${ }^{\mathrm{kd}}$ cells, fluorescence of DRP1 (red) reduced markedly, and the mitochondria (green fluorescence) became more filamentous (the second row of images) than the control cells (the first row of images). 
filamentous (Figure 1d2). These results validated that our monoclonal antibodies recognized DRP1.

\section{Expression of DRP1 in Lung Adenocarcinomas and Correlation with Patients' Survival}

Using DRP1-specific monoclonal antibodies, we detected DRP1 overexpression in tumor cells in specimens from 202 patients (89.0\%) with lung adenocarcinomas (Figure 2a1 and a2). The DRP1 signal was identified in nuclei of tumor cells (Figure 2a2) in 184 (91.1\%) of the 202 patients. Nuclear DRP1 (DRP1 ${ }^{\text {nuc }}$ ) was detected in $91.2 \%$ (52 of 57) of metastatic lymph nodes. Interestingly, some of the nuclear DRP1 signal was located in nucleoli (Figure 2a2). Overexpression of DRP1 (17 of 20) in tumor specimens was verified by immunoblotting (Figure 2b). Statistical analysis showed that expression of DRP $1^{\text {nuc }}$ correlated with tumor staging and cigarette smoking (Tables 1 and 2). Smokers and patients with later stages of lung adenocarcinomas are more likely to express nuclear DRP1.

Among the 202 patients who had high DRP1 $1^{\text {nuc }}$ levels, 115 (56.9\%) had tumor recurrence during follow-up examination. Among 18 patients who had cytoplasmic DRP1 (DRP1 ${ }^{\text {cyt }}$ ), 3 (16.7\%) patients had tumor recurrence. All 118 patients developed new tumors within 18 months after operation. The recurrence rate in patients with DRP1 ${ }^{\text {nuc }}$ was 3.41 fold higher than that in patients with DRP1 ${ }^{\text {cyt }}$. The difference was significant $(P<0.01)$. No significant difference was found in cumulative survival between patients with high DRP1 levels and those with low DRP1 levels (Figure 2c1). However, survival of patients with high DRP1 ${ }^{\text {cyt }}$ levels was significantly better than survival of patients with high DRP1 ${ }^{\text {nuc }}$ levels and those in whom DRP1 was not detected (Figure 2c2 and c3; $P<0.001$ ). When patients were divided into groups by each of clinicopathological parameters, significant difference by univariate analysis was found in tumor stage $(P<0.001)$ lymph node involvement $(P<0.001)$, DRP1 expression $(P<0.001)$ and gender $(P=0.0294)$ (Table 3). In multivariate analysis, tumor stage $(P<0.001)$, lymph node involvement $(P=0.004)$ and DRP1 expression $(P=0.135)$ remained significant. No statistical difference was found in cell differentiation or cigarette smoking.

\section{Increased Nuclear Localization of DRP1 and Survival Following Exposure to Hypoxia in Lung Adenocarcinoma Cells}

In vitro, exposure to hypoxic conditions did not affect mRNA level of hypoxia-inducible factor- $1 \alpha$ $(\mathrm{HIF}-1 \alpha)$ or DRP1 (Figure 3a1) in H838 cells, but significantly influenced the protein levels of HIF-1 $\alpha$ and phosphorylated DRP1 (Figure 3a2). Partial degradation of DRP1 in the early phase of hypoxia (around 1-3 h) suggested that DRP1 could be labile in the cytoplasm. Hypoxia increased cell resistance to cisplatin (Figure $3 \mathrm{~b}$ ) as well as the levels of nuclear and nucleolar DRP1, which were determined by confocal immunofluorescence microscopy (Figure 3c, the second row of images). Knockdown of human homologue of yeast Rad23 protein A (hHR23A), however, decreased hypoxia-induced cytoprotection of cisplatin toxicity in H838 cells. Earlier treatment with RNAse, however, reduced nucleolar levels of DRP1 (Figure 3c, the third row of images). Immunoblotting analysis of subcellular components confirmed our findings that DRP1 was located in the nucleus following exposure to hypoxia (Figure 3d). The nuclear DRP1 was mostly phosphorylated. Overexpression of ectopic DRP1 ${ }^{\mathrm{WT}}$, but not DRP1 ${ }^{\text {K38A }},{ }^{9}$ increased nucleolar DRP1 and autophagic vesicles indicating that excessive cytoplasmic DRP1 could be able to trigger autophagy and became harmful to cells (Figure 3e). Hypoxia also increased the formation of autophagic vesicles, which were encircled by hHR23A and DRP1 (Figure 3f). However, protein sequence analysis did not show that DRP1 contains a nuclear localization signal (Supplementary Figure 1). Nuclear translocation of DRP1 might, thus, require a transporting vehicle. Using DRP1 as bait to screen a cytoplasmic protein library, we found that hHR23A reacted with DRP1.

\section{Antibodies Specific to DRP1 Precipitates hHR23A and Repression of hHR23A Expression Decreases Hypoxia-Induced Nuclear Translocation of DRP1}

We used immunoprecipitation method to verify that DRP1 interacts with hHR23A. Monoclonal antibodies specific to DRP1 precipitated both DRP1 and hHR23A (Figure 4a, left panel) from the wholecell lysate. Likewise, monoclonal antibodies specific to hHR23A precipitated both hHR23A and DRP1 (Figure 4a, center panel). Using monoclonal antibodies specific to green fluorescent protein (GFP), we precipitated both hHR23A and DRP1EGP, of which an enhanced green fluorescent protein (EGP) was conjugated at the $C$ terminus of DRP1, as well as pDRP1-EGP (Figure 4a, right panel). These results suggest that DRP1 directly interacts with hHR23A.

Interestingly, using hHR23A-specific siRNAs to knock down hHR23A expressions also reduced protein levels of DRP1 (Figure 4b, left panel). Ectopic replenish of hHR23A expression recovered DRP1 expression (Figure 4b, right panel). The phenomena were confirmed by confocal immunofluorescence microscopy (Figure 4c, the second row of images). Although short-term hypoxia increased nuclear and nucleolar DRP1 (Figure 4c, the third row of images), silence of hHR23A expression clearly decreased nuclear translocation of DRP1 (Figure 4c, fourth row of images). These results suggest that hHR23A is involved in nuclear transportation of DRP1. 
DRP1 Interacts with AMPK and Silence of AMPK Expression Decreases DRP1 Phosphorylation

Antibodies specific to AMP-activated protein kinase (AMPK) precipitated both AMPK and DRP1 from cell lysate of H838 cells (Figure 5a), indicating that AMPK and DRP1 interacted with each other. Silence of AMPK expression by siRNA reduced hypoxia-induced DRP1 phosphorylation (Figure 5b), suggesting that AMPK is involved in phosphorylation of DRP1 during hypoxia.
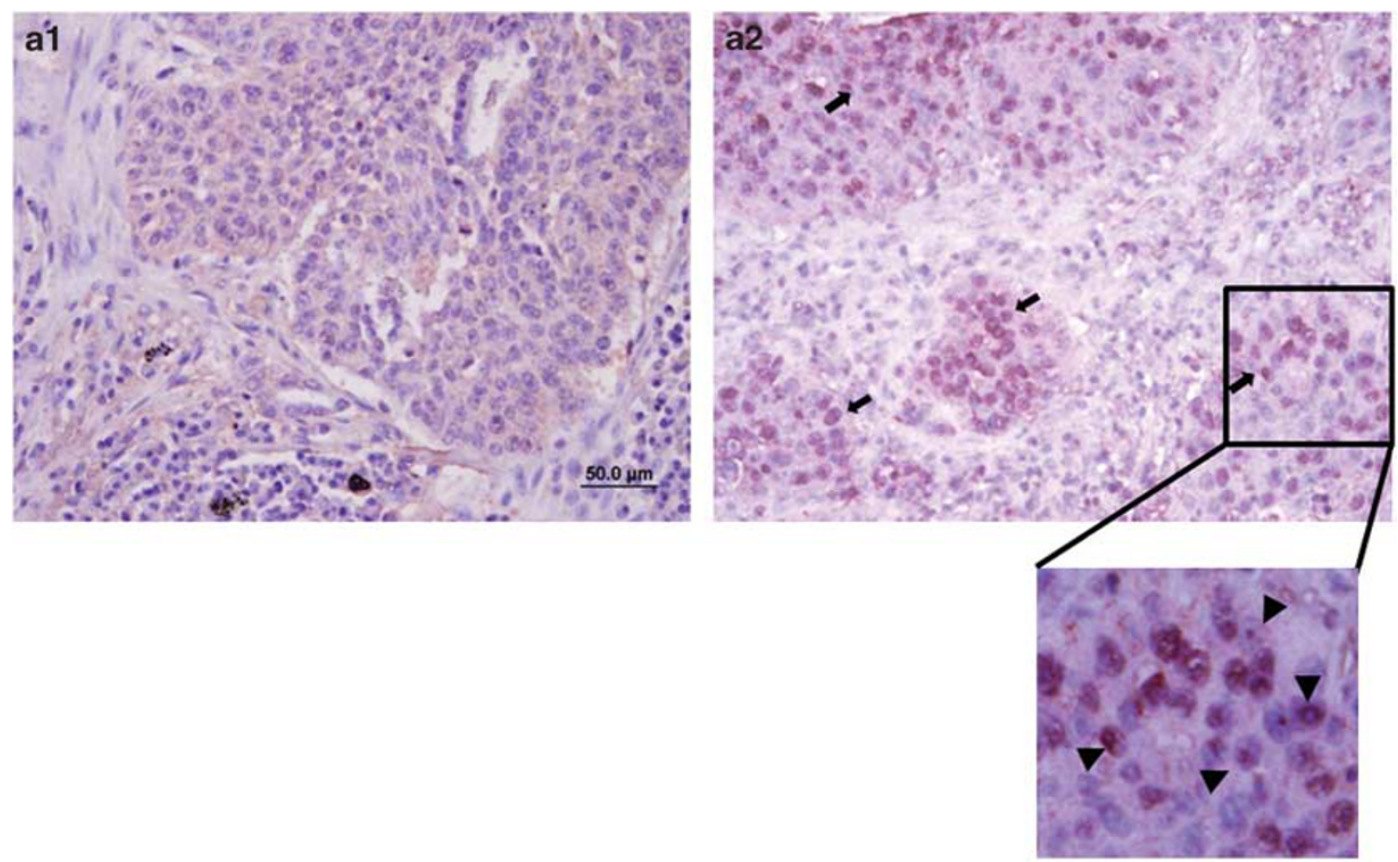

b

lb

Stage

$\frac{1}{N T} \frac{2}{N T} \frac{3}{N T} \frac{4}{N T} \frac{5}{N T} \frac{6}{N T} \frac{7}{N T} \frac{8}{N T} \frac{9}{N T} \frac{10}{N T}$

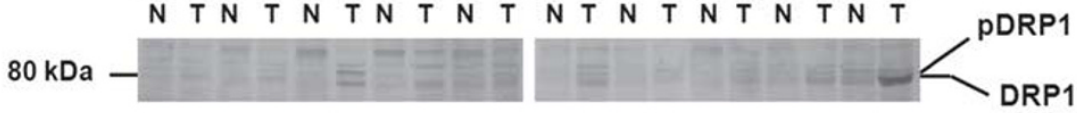

$42 \mathrm{kDa}-6=0-50-0$
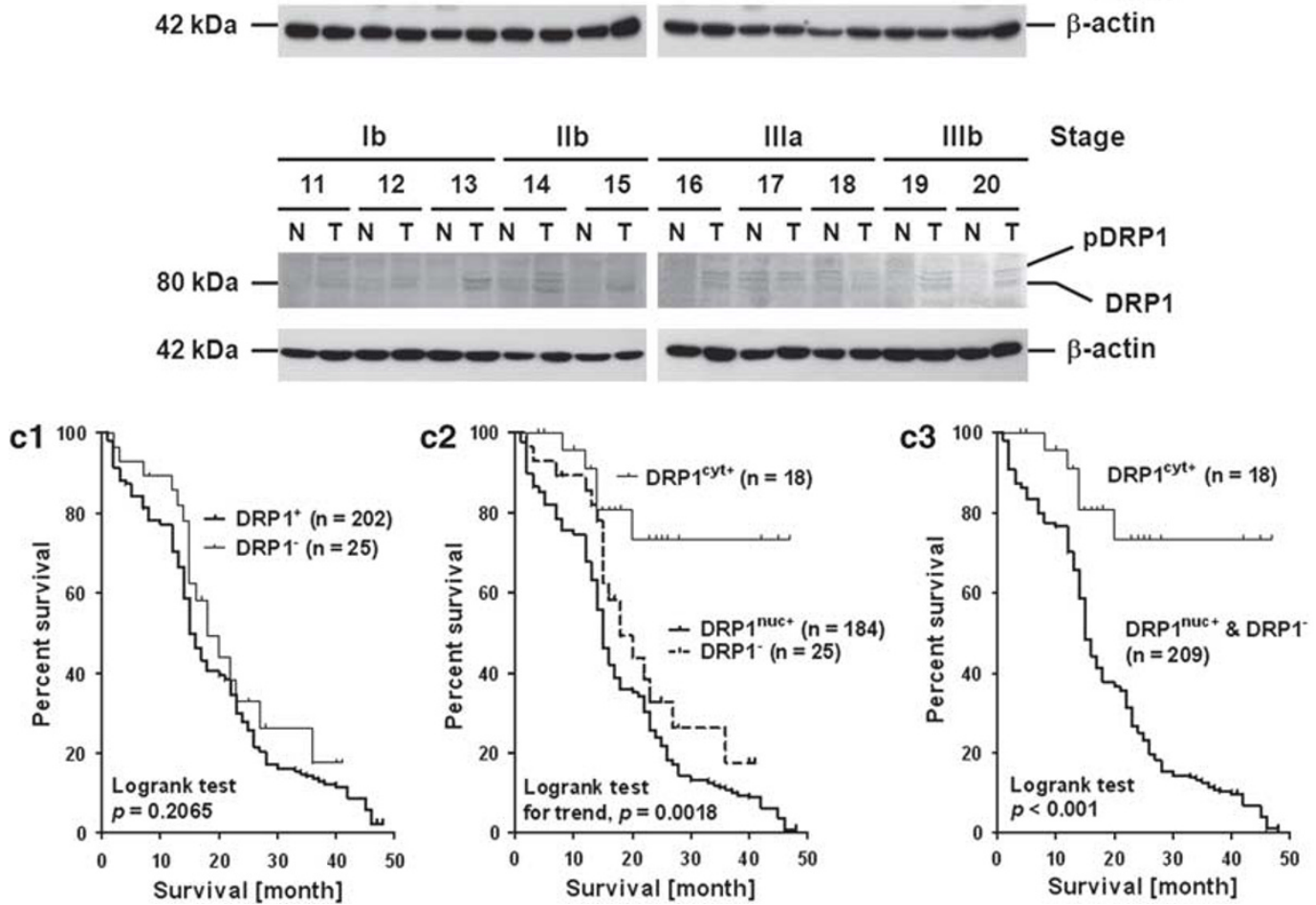


\section{Discussion}

The results show that antibodies generated in this study recognized the functional DRP1, which is normally present on mitochondria, ${ }^{5-8}$ as well as nuclear and nucleolar DRP1 (DRP1 ${ }^{\text {nuc }}$ ), which is frequently detected in pathological sections of lung adenocarcinomas and in hypoxic cells. Correlation of DRP1 ${ }^{\text {nuc }}$ expression with the advanced tumor stage and patients' cigarette-smoking habits suggests that DRP1 ${ }^{\text {nuc }}$ expression is associated with cigarette

Table 1 Correlation of DRP1 expression with clinicopathological parameters in patients with lung adenocarcinomas

\begin{tabular}{|c|c|c|c|}
\hline \multirow{2}{*}{$\begin{array}{l}\text { Clinicopathological } \\
\text { parameter }\end{array}$} & \multicolumn{2}{|c|}{ Expression of DRP1 } & \multirow[t]{2}{*}{ P-value } \\
\hline & $\operatorname{High}(\mathrm{n}=202)$ & $\operatorname{Low}(\mathrm{n}=25)$ & \\
\hline \multicolumn{4}{|l|}{ Gender } \\
\hline Male $(n=167)$ & 145 & 22 & $0.096^{\mathrm{a}}$ \\
\hline Female $(n=60)$ & 87 & 3 & \\
\hline \multicolumn{4}{|l|}{ Cigarette smoking } \\
\hline Smoker $(n=145)$ & 126 & 19 & $0.181^{\mathrm{b}}$ \\
\hline Nonsmoker $(n=82)$ & 76 & 6 & \\
\hline \multicolumn{4}{|l|}{ Stage } \\
\hline $\mathrm{I}(n=109)$ & 93 & 16 & $0.205^{\mathrm{b}}$ \\
\hline II $(n=89)$ & 83 & 6 & \\
\hline III $(n=29)$ & 26 & 3 & \\
\hline \multicolumn{4}{|l|}{ Cell differentiation } \\
\hline Well $(n=32)$ & 30 & 2 & $0.597^{\mathrm{b}}$ \\
\hline Moderate $(n=126)$ & 112 & 14 & \\
\hline Poor $(n=69)$ & 60 & 9 & \\
\hline \multicolumn{4}{|c|}{ Lymphovascular invasion } \\
\hline Positive $(n=192)$ & 173 & 19 & $0.238^{\mathrm{b}}$ \\
\hline Negative $(n=35)$ & 29 & 6 & \\
\hline
\end{tabular}

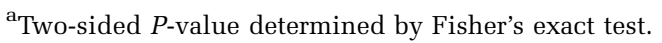

b Two-sided $P$-value determined by $\chi^{2}$-test or $\chi^{2}$-test for trend.

Figure 2 Expression of DRP1 and its correlation with survival in lung adenocarcinomas. (a) Representative examples of DRP1 expression in lung adenocarcinoma cells. (a1) Expression of DRP1 was detected by immunohistochemistry (as crimson precipitates in cytoplasm). (a2) DRP1 signals were detected in nuclei (indicated by arrows) and nucleoli (indicated by arrowheads) of some tumor cells. (b) Expression of DRP1 was confirmed by immunoblotting. Expression of $\beta$-actin was used as a monitoring standard. (c) Comparison of Kaplan-Meier product limit estimates of survival analysis in patients with lung adenocarcinomas. (c1) Patients were divided into two groups based on DRP1 expression in pathological specimens of lung adenocarcinomas. DRP1 ${ }^{-}$, low DRP1 expression; DRP1 ${ }^{+}$, high DRP1 expression. Survival difference between the two groups was compared by a log-rank test $(P=0.3871)$. (c2) Patients were divided into three groups based on DRP1 expression and location of DRP1 in the lung adenocarcinoma cells. The survival rate of patients in the group with cytoplasmic DRP1 only (DRP1 $\left.1^{\text {cyt }+}\right)$ was better than that of patients in the other two groups: DRP1- and DRP1 nucleus-positive (DRP1 ${ }^{\text {nuc }+}$ ) groups. Survival difference between the three groups was compared by a log-rank test for trend $(P<0.01)$. (c3) The difference was also significant when DRP1 ${ }^{-}$ and DRP1 $1^{\text {nuc }+}$ groups were pooled and the survival was compared by a log-rank test $(P<0.001)$. smoking, and, possibly, the hypoxic environment. In vitro, hypoxia increased levels of DRP1 $1^{\text {nuc }}$ expression and that of drug resistance in lung

Table 2 Correlation of DRP1 ${ }^{\text {nuc }}$ expression with clinicopathological parameters in patients with lung adenocarcinomas

\begin{tabular}{lll}
\hline $\begin{array}{l}\text { Clinicopathological } \\
\text { parameter }\end{array}$ & \multicolumn{2}{c}{ Expression of DRP1 } \\
\cline { 2 - 3 } & $\begin{array}{c}D R P 1^{\text {nuc }} \\
(\mathrm{n}=184)\end{array}$ & $\begin{array}{c}D R P 1^{\text {cyt }} \\
(\mathrm{n}=18)\end{array}$ \\
\hline
\end{tabular}

\begin{tabular}{lrrl}
\hline Gender & & & \\
$\quad$ Male $(n=145)$ & 128 & 17 & $0.027^{\mathrm{a}}$ \\
$\quad$ Female $(n=57)$ & 56 & 1 & \\
& & & \\
Cigarette smoking & & 5 & $0.002^{\mathrm{b}}$ \\
$\quad$ Smoker $(n=126)$ & 121 & 13 & \\
$\quad$ Nonsmoker $(n=76)$ & 63 & & \\
Stage & & 15 & $0.003^{\mathrm{b}}$ \\
I $(n=93)$ & 78 & 3 & \\
II $(n=83)$ & 80 & 0 & \\
III $(n=26)$ & 26 & & \\
& & 5 & $0.187^{\mathrm{b}}$ \\
Cell differentiation & & 10 & \\
$\quad$ Well $(n=30)$ & 25 & 3 & \\
Moderate $(n=112)$ & 102 & & \\
Poor $(n=60)$ & 57 & & \\
Lymphovascular invasion & & 6 & \\
Positive $(n=173)$ & 161 & & \\
$\quad$ Negative $(n=29)$ & 23 & & \\
\end{tabular}

aTwo-sided $P$-value determined by Fisher's exact test.

${ }^{\mathrm{b}}$ Two-sided $P$-value determined by $\chi^{2}$-test or $\chi^{2}$-test for trend.

Table 3 Survival analysis of patients with lung adenocarcinomas

\begin{tabular}{|c|c|c|}
\hline \multirow{2}{*}{$\begin{array}{l}\text { Clinicopathological parameter } \\
\text { (number of patients) }\end{array}$} & \multicolumn{2}{|c|}{$\mathrm{P}$-value } \\
\hline & $\begin{array}{l}\text { Univariate } \\
\text { analysis }\end{array}$ & $\begin{array}{c}\text { Multivariate } \\
\text { analysis }\end{array}$ \\
\hline $\begin{array}{l}\text { Gender } \\
\quad \text { Male }(n=167) \\
\text { Female }(n=60)\end{array}$ & 0.0294 & 0.187 \\
\hline $\begin{array}{l}\text { Cigarette smoking } \\
\quad \text { Smoker }(n=145) \\
\text { Nonsmoker }(n=82)\end{array}$ & 0.2715 & \\
\hline $\begin{array}{l}\text { Stage } \\
\quad \text { I }(n=109) \\
\text { II+III }(n=118)\end{array}$ & $<0.001$ & $<0.001$ \\
\hline $\begin{array}{l}\text { Histological grade } \\
\quad \text { Well differentiated }(n=32) \\
\quad \geq \text { Moderately }(n=195)\end{array}$ & 0.2167 & \\
\hline $\begin{array}{l}\text { Lymphovascular invasion } \\
\text { Positive }(n=192) \\
\text { Negative }(n=35)\end{array}$ & $<0.001$ & 0.004 \\
\hline $\begin{array}{l}\text { DRP1 expression } \\
\quad \text { Nuclear+negative }(n=209) \\
\text { Cytoplasm }(n=18)\end{array}$ & $<0.001$ & 0.0135 \\
\hline
\end{tabular}



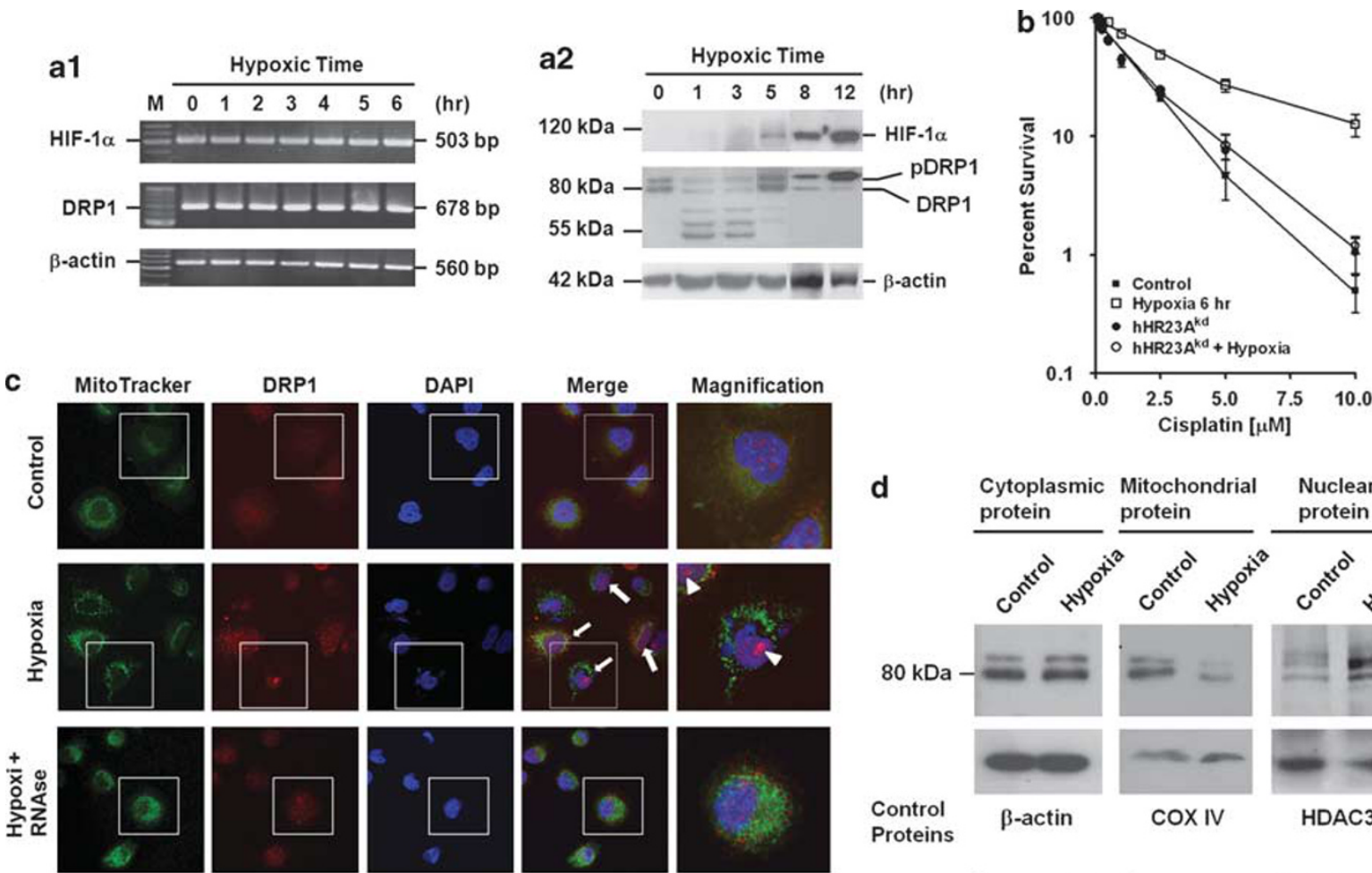

Proteins

$\beta$-actin

COXIV

Nuclear

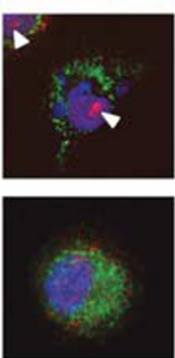
protein
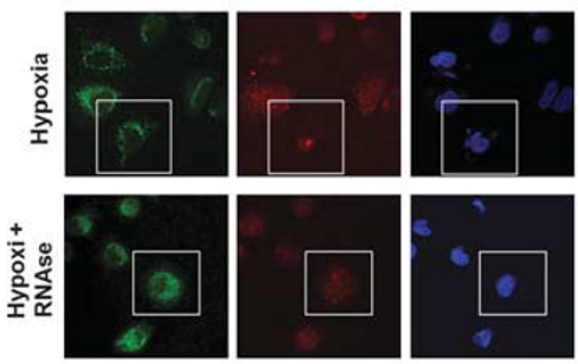

e

Control

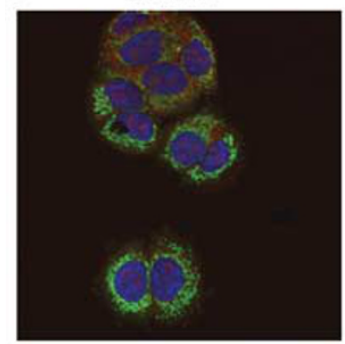

Ectopic DRP1wT

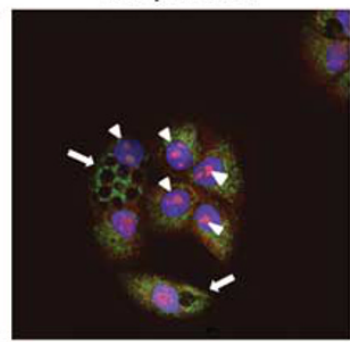

Ectopic DRP1 ${ }^{\text {K38A }}$

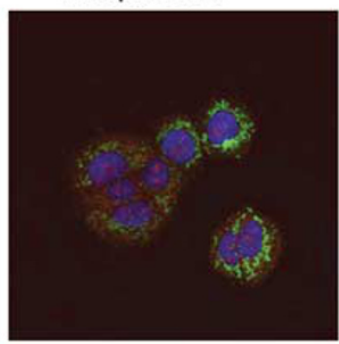

$f$

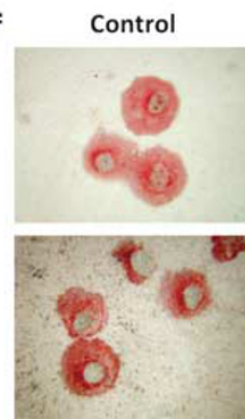

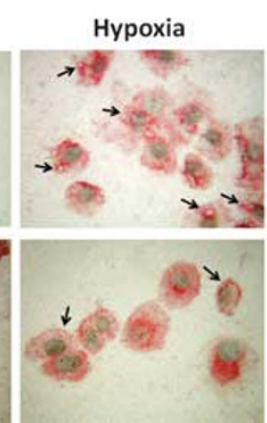

hHR23A

DRP1

Figure 3 Hypoxia induced nuclear localization of DRP1. (a) Exposure of hypoxia increased nuclear localization of DRP1 and cell survival in lung adenocarcinoma cells, H838. (a1) In vitro, following exposure of hypoxia for 2-6 h, no evident change in mRNA levels of hypoxiainducible factor- $1 \alpha$ (HIF-1 $\alpha$ ) and DRP1 was detected in H838 cells; however (a2) protein levels of HIF-1 $\alpha$ and the phosphorylated DRP1 (pDRP1) increased significantly after hypoxic treatment. (b) Hypoxic treatment for $6 \mathrm{~h}$ reduced the cisplatin toxicity in H838 cells. Knockdown of hHR23A decreased hypoxia-induced cytoprotection of cisplatin toxicity in H838 cells. (c) Immunofluorescence confocal microscopy showed that hypoxia increased levels of nuclear (indicated by arrows, the second row of images) and nucleolar (indicated by arrowheads in the magnified images) DRP1. Earlier treatment with RNAse did not affect nuclear levels, but reduced nucleolar levels of DRP1 (the third row of images). (d) Immunoblotting analysis of subcellular components showed that hypoxia increased nuclear levels of DRP1 and pDRP1. (e) Overexpression of ectopic DRP1 ${ }^{\mathrm{WT}}$, but not DRP1 ${ }^{\mathrm{K} 38 \mathrm{~A}}$ increased autophagy-like vesicles (arrows) and nucleolar DRP1 (arrowheads) in H1437 cells. (f) Hypoxia increased autophagy-like vesicles, which were encircled by hHR23A and DRP1 (indicated by arrows) in H838 cells.

cancer cells. Moreover, these data indicate that intracellular distribution of DRP1 is essential for determining drug sensitivity of lung adenocarcinomas, which then reflects in patients' survivals. Patients, who have DRP1 in cytoplasm, probably on mitochondria, are more sensitive to chemotherapy and have better prognosis. Conversely, patients, who have undetectable level of cytoplasmic DRP1 or those in whom DRP1 is sequestered to the nucleus are more resistant to chemotherapy and, therefore, have worse prognosis.

Hypoxia is frequently detected in advanced solid tumors and is associated with increased drug resistance in cancer cells. ${ }^{18,19}$ The increase in drug resistance has been attributed to the expression of multidrug resistance 1 protein, MDR-associated protein and antiapoptotic Bcl-2 protein. Interestingly, hypoxia and genotoxic stress have also been reported to increase nuclear levels of apoptosisrelated mitochondrial proteins, eg, Bcl-2, Bcl-2 $19 \mathrm{kDa}$ interacting protein 3 (BNIP3), ${ }^{20,21}$ apoptotic protease-activating factor 1 and 'BH3-only' proapoptotic protein BID. ${ }^{21-24}$ These proteins do not contain evident nuclear localization signals, but they do contain a potential DNA- and RNA-binding motifs (Supplementary Figure 1) and they are 'located in 
a

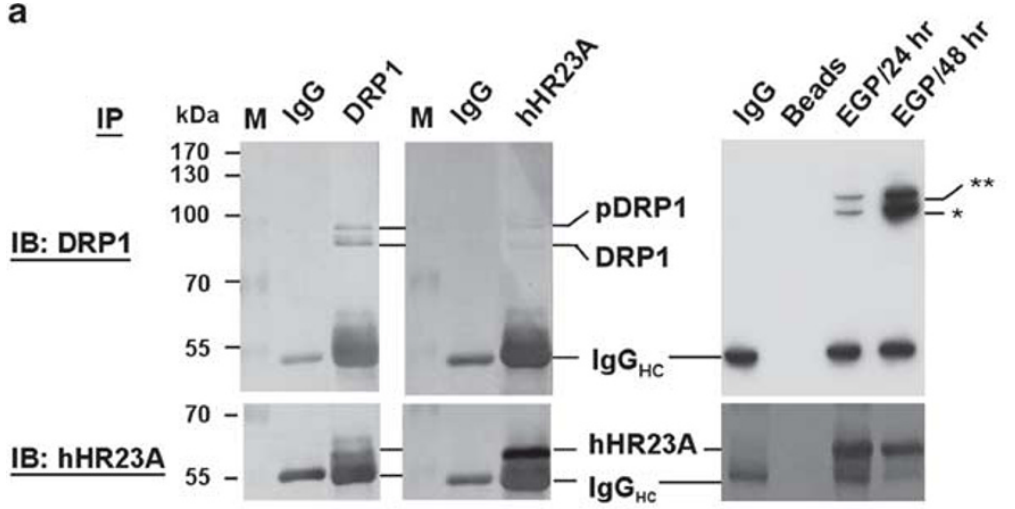

C
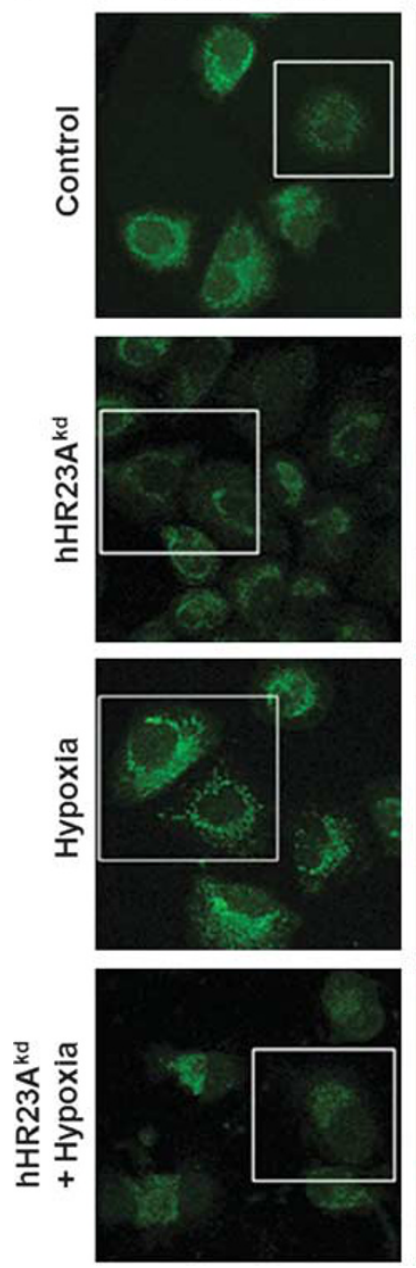

DRP1
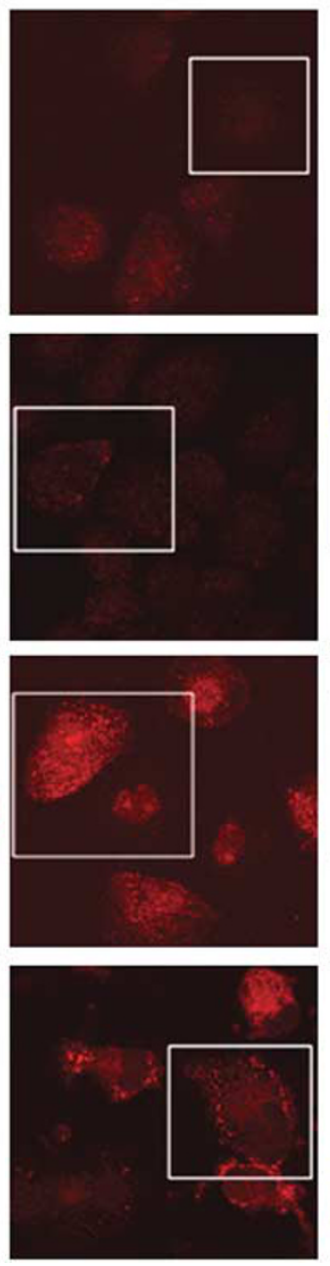

b

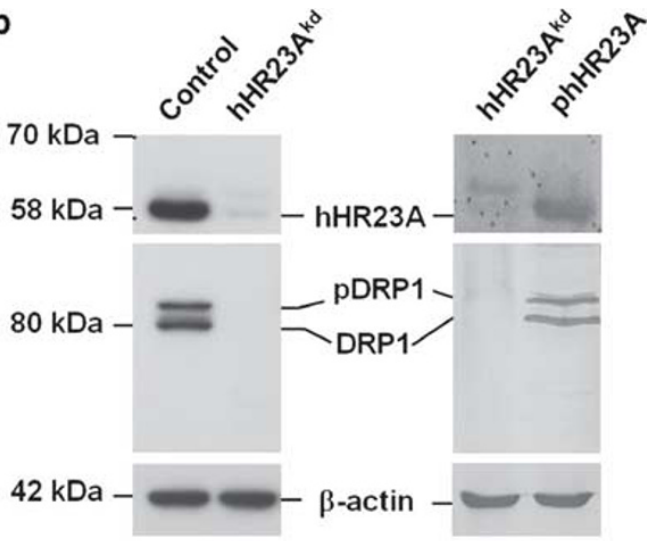

DAPI
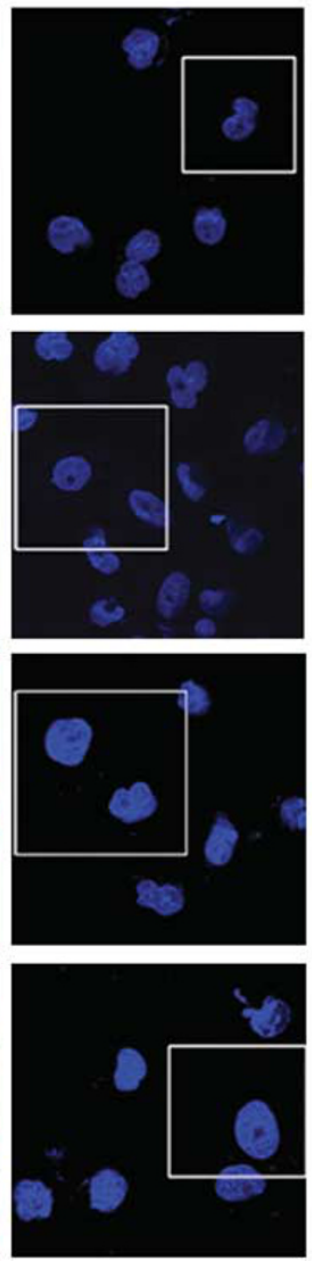

Merge
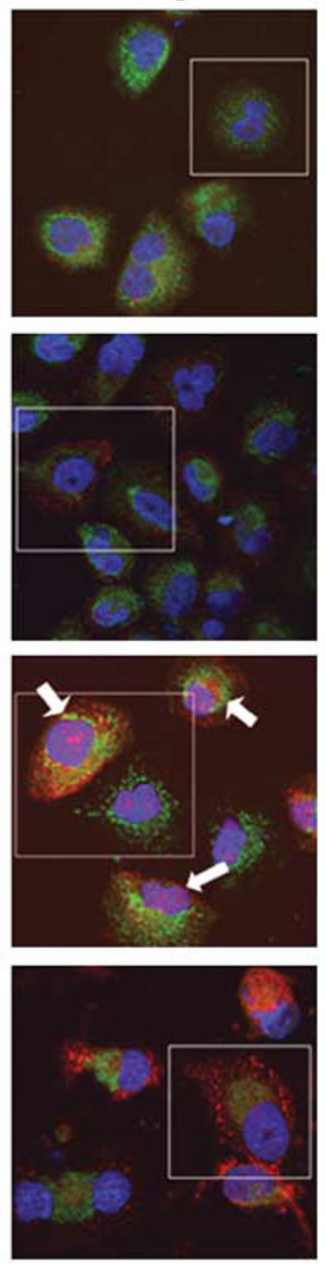

Magnification
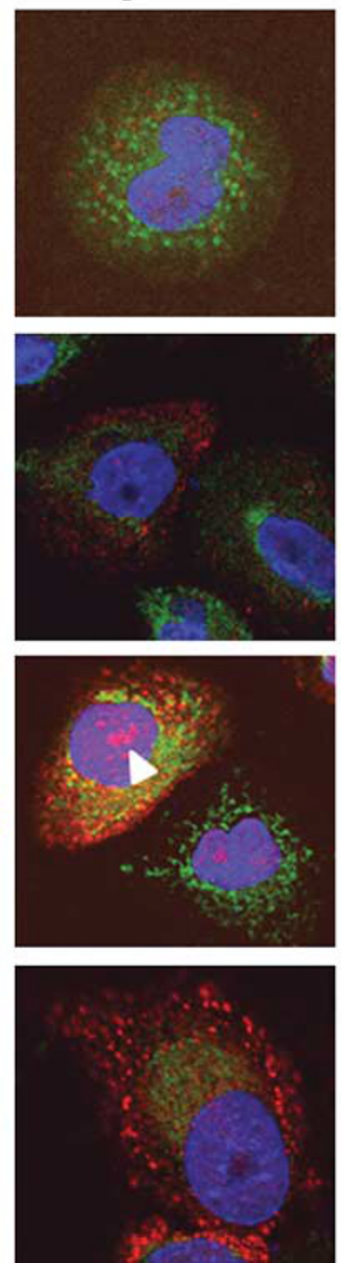

Figure 4 DRP1 interacts with hHR23A, and knockdown of hHR23A expression decreases hypoxia-induced nuclear translocation of DRP1. (a) Monoclonal antibodies specific to DRP1 precipitated DRP1 and hHR23A (left panel) from the whole-cell lysate of H838 by Protein G Sepharose. Likewise, antibodies specific to hHR23A precipitated both hHR23A and DRP1 (center panel). Monoclonal antibodies specific to green fluorescent protein (GFP) precipitated both DRP1-EGP $\left({ }^{*}\right)$ and pDRP1-EGP $\left({ }^{* *}\right)$ as well as hHR23A (left panel). These data suggest that DRP1 could directly interact with hHR23A. (b) Treatment with hHR23A-specific siRNAs reduced the protein level of $58 \mathrm{kDa}$ hHR23A (left upper panel) as well as that of DRP1 (left lower panel). Ectopic replenish of hHR23A expression by mammalian plasmid carrying hHR23A gene (phHR23A) recovered DRP1 expression (right panel). (c) Treatment of H838 cells with hHR23A-specific siRNA reduced DRP1 levels as observed by confocal fluorescence immunocytochemistry (second row images), and the residual of DRP1 (red fluorescence) was not overlapped with the fluorescent images of mitochondria (green fluorescence). Exposure to hypoxia evidently increased nuclear (arrows) and nucleolar (arrowhead) DRP1 (third row images). Inhibition of hHR23A expression clearly reduced nuclear DRP1 (fourth row images). 
1148 a

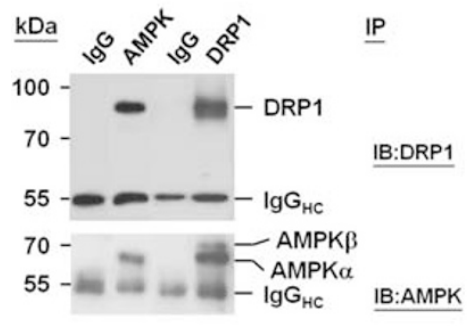

b
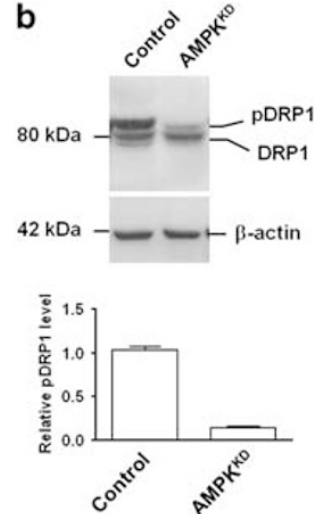

$42 \mathrm{kDa}--(-\beta$-actin

Figure 5 DRP1 interacts with AMP-activated protein kinase (AMPK), and knockdown of AMPK expression decreases phosphorylation of DRP1. (a) Monoclonal antibodies specific to AMPK precipitated both AMPK (left panel) and DRP1 (right panel) from the whole-cell lysate of H838 by Protein G Sepharose. These data suggest that DRP1 could directly interact with AMPK. (b) Knockdown of AMPK expression by specific siRNAs reduced the level of DRP1 phosphorylation after $12 \mathrm{~h}$ of hypoxia.

the nucleus' when cells were exposed to hypoxia or genotoxic stress. Recent studies have shown that these proteins are involved in cell-cycle progression and DNA repair, processes that are mediated by ataxia telangiectasia mutated (ATM) as well as ATM and rad3-related (ATR) kinases. Nuclear localization of these proteins could increase genomic instability as well as radiation and drug resistance. ${ }^{24,25}$ However, nuclear transportation mechanisms of these proteins are not clearly illustrated.

It is worth noting that DRP1 has been detected in the 'nuclei and nucleoli'. ${ }^{9,26-28}$ The nuclear and nucleolar accumulation became more evident when cells were exposed to hypoxia. Increased nuclear levels of DRP1 correlated with drug resistance. Moreover, using antibodies specific to DRP1 and hHR23A, we found that these two proteins interact with each other. Silencing of hHR23A reduces the levels of DRP1 ${ }^{\text {nuc }}$ and cisplatin resistance. These data suggest that hHR23A is essential for the accumulation of DRP1 $1^{\text {nuc }}$ and for cisplatin resistance. It should be noted, however, that other explanations are possible. For instance, like yeast Rad23 human homologues, hHR23A and hHR23B have been proposed having crucial functions in nucleotide excision repair. ${ }^{29}$ Nuclear imports of hHR23A and hHR23B are crucial for adequate DNA repair. Nuclear transport of these two proteins, which do not contain evident NLS, however, has not been clearly illustrated. The fact that knockout of hHR23B but not that of hHR23A gene in mice generated severe facial disfigurement and male infertility suggests that the physiological functions of hHR23A might be different from those of hHR23B. ${ }^{30}$ Withers-Ward et $a l^{31}$ showed that hHR23A, by interacting with viral protein $\mathrm{R}$ of human immunodeficiency virus (HIV), facilitates nuclear import of pre-integration complex for HIV replication. The presence of hHR23A inhibits p53 degradation and increases apoptosis, ${ }^{32}$ which could be possibly through the association with p14ARF to sequester human double minute 2 (HDM2) protein in nucleoli and to relieve nuclear p53 from HDM2mediated proteolysis. ${ }^{33}$ These results, considered together with our current data, clearly suggest that hHR23A as well as karyopherins ${ }^{34}$ might be important in emergency nuclear transport of DRP1 to protect genomic and nucleolar DNA when cells are subjected to hypoxic conditions (Supplementary Figure 2).

As noted above, BNIP3, an important ARM protein, induces PCD through apoptosis and autophagy. ${ }^{20,21}$ Increased nuclear level of BNIP3, on the other hand, reduces cell sensitivity to hypoxia- and ischemia-induced damages. ${ }^{21}$ Interestingly, DRP1 is involved in all three types of PCD. ${ }^{2-4}$ The current study showed that hypoxia increased the nuclear levels of DRP1 and the level of cisplatin resistance in lung adenocarcinoma cells. In an elegant review, Conradt ${ }^{35}$ proposed that DRP1 might be recruited by an $\mathrm{X}$ factor that promotes DRP1 binding to hFis1 on mitochondrial outer membrane and initiates mitochondrial fission. However, Conradt's hypothesis did not offer a mechanism of DRP1 activation. Our results, more or less, suggest that hHR23A might act as an $\mathrm{X}$ factor, which was activated by hypoxia, to protect cells by redistributing DRP1 to the nucleus (1) to prevent excessive mitochondrial fission or (2) to guard genomic DNA and nucleolar RNA against hypoxia-induced damage through a potential nucleotide-binding motif on DRP1 (Supplementary Figure 1). In this case, our results provide a reasonable explanation for the involvement of DRP1, a mechanoenzyme that mediates organelle membrane constrictions, ${ }^{7,8}$ in type II programmed cell death and in the formation of autophagic vesicles, ${ }^{2-4}$ which were corralled by both DRP1 and hHR23A. In particular, when cells were exposed to short-term hypoxia, the autophagic vacuoles as well as nuclear and nucleolar DRP1 emerged more prominently.

Taguchi et $a l^{6}$ showed that DRP1 phosphorylation by cyclin-dependent kinase 1 (cdk1)/cyclin B is critical for mitochondrial fission during the mitotic (M) phase. Interestingly, cdk1/cyclin B protein complex is regulated by ATM/ATR kinases, which are transported in and out of the nucleus depending on the progression phases of cell cycle. ${ }^{36,37}$ Our data, which show that phosphorylation and nuclear translocation of DRP1 occur simultaneously with the increase in HIF-1 $\alpha$, support their findings. Moreover, our data show that the level of DRP1 rises during the $S$ phase. The extent of DRP1 phosphorylation, however, is not changed throughout the cell-cycle progression (Supplementary Figure 3). These results are consistent with the fact that although anticancer drugs induce growth arrest of cells at $\mathrm{G}_{2} / \mathrm{M}$, the major cytotoxic function is S-phase dependent. ${ }^{15}$ Moreover, because short-term 
hypoxia alone does not immediately induce visible DNA damage in cancer cells per se, by showing that DRP1 interacts with AMPK, and that silencing of AMPK reduces phosphorylation and nuclear translocation of DRP1, our data clearly indicate that AMPK is responsible for hypoxia-related phosphorylation of DRP1, ${ }^{38,39}$ and hHR23A binds phosphorylated DRP1.

In conclusion, immunohistochemistry revealed abundant nuclear expression of DRP1 in lung adenocarcinomas. Pathological results suggest that nuclear and nucleolar DRP1 (DRP1 ${ }^{\text {nuc }}$ ) are associated with poor prognosis. In vitro, hypoxia increased the expression of DRP1 $1^{\text {nuc }}$ and the level of cisplatin resistance in lung adenocarcinoma cells. By showing that DRP1 and hHR23A interact with each other, and that silencing of hHR23A decreased the nuclear translocation of DRP1 as well as cisplatin resistance, our results suggest that nuclear transport of pDRP1 might have a role in increasing drug resistance of lung cancer cells during hypoxia.

\section{Acknowledgement}

We thank Dr S-H Chiou for critically reading the paper. This study was supported in part by a grant from the Research Fund of Feng-Yuan Hospital (FYHIRF 96-001), Feng-Yuan, Taiwan; and, in part, by the Comprehensive Academic Promotion Projects (NCHU 975014, Department of Education, Executive Yuan, Republic of China, to KC Chow).

\section{References}

1 Gozuacik D, Kimchi A. Autophagy as a cell death and tumor suppressor mechanism. Oncogene 2004;23:2891-2906.

2 Bras M, Yuste VJ, Roué G, et al. Drp1 mediates caspaseindependent type III cell death in normal and leukemic cells. Mol Cell Biol 2007;27:7073-7088.

3 Frank S, Gaume B, Bergmann-Leitner ES, et al. The role of dynamin-related protein 1, a mediator of mitochondrial fission, in apoptosis. Dev Cell 2001;1:515-525.

4 Barsoum MJ, Yuan H, Gerencser AA, et al. Nitric oxideinduced mitochondrial fission is regulated by dynamin-related GTPases in neurons. EMBO J 2006; 25:3900-3911.

5 Waterham HR, Koster J, van Roermund CW, et al. A lethal defect of mitochondrial and peroxisomal fission. N Engl J Med 2007;356:1736-1741.

6 Taguchi N, Ishihara N, Jofuku A, et al. Mitotic phosphorylation of dynamin-related GTPase Drp1 participates in mitochondrial fission. J Biol Chem 2007;282:11521-11529.

7 Mozdy AD, McCaffery JM, Shaw JM. Dnm1p GTPasemediated mitochondrial fission is a multi-step process requiring the novel integral membrane component Fis1p. J Cell Biol 2000;151:367-380.

8 Youle RJ, Karbowski M. Mitochondrial fission in apoptosis. Nat Rev Mol Cell Biol 2005;6:657-663.
9 Lee YJ, Jeong SY, Karbowski M, et al. Roles of the mammalian mitochondrial fission and fusion mediators Fis1, Drp1, and Opa1 in apoptosis. Mol Biol Cell 2004;15:5001-5011.

10 Tacka KA, Szalda D, Souid AK, et al. Experimental and theoretical studies on the pharmacodynamics of cisplatin in jurkat cells. Chem Res Toxicol 2004; 17:1434-1444.

11 Elder RT, Song XQ, Chen M, et al. Involvement of rhp23, a Schizosaccharomyces pombe homolog of the human HHR23A and Saccharomyces cerevisiae RAD23 nucleotide excision repair genes, in cell cycle control and protein ubiquitination. Nucleic Acids Res 2002;30:581-591.

12 Marignol L, Coffey M, Lawler M, et al. Hypoxia in prostate cancer: a powerful shield against tumour destruction? Cancer Treat Rev 2008;34:313-327.

13 Mountain CF. Revisions in the International System for Staging Lung Cancer. Chest 1997;111:1710-1717.

14 Chen JT, Lin TS, Chow KC, et al. Cigarette smoking induces overexpression of hepatocyte growth factor in type II pneumocytes and lung cancer cells. Am J Respir Cell Mol Biol 2006;34:264-273.

15 Chow KC, Ross WE. Topoisomerase specific drug sensitivity in relation to cell cycle progression. Mol Cell Biol 1987;7:3119-3123.

16 Kaplan EL, Meier P. Nonparametric estimation from incomplete observations. J Am Stat Assoc 1958; 53:457-481.

17 Mantel N. Evaluation of survival data and two new rank order statistics arising in its consideration. Cancer Chemother Rep 1966;50:163-170.

18 Martin J. Exploiting the hypoxic cancer cell: mechanisms and therapeutic strategies. Mol Med Today 2000; 6:157-162.

19 Koch S, Mayer F, Honecker F, et al. Efficacy of cytotoxic agents used in the treatment of testicular germ cell tumours under normoxic and hypoxic conditions in vitro. Br J Cancer 2003;89:2133-2139.

20 Daido S, Knzawa T, Yamamoto A, et al. Pivotal role of the cell death factor BNIP3 in ceramide-induced autophagic cell death in malignant glioma cells. Cancer Res 2004;64:4286-4293.

21 Burton TR, Henson ES, Baijal P, et al. The pro-cell death Bcl-2 family member, BNIP3, is localized to the nucleus of human glial cells: implications for glioblastoma multiforme tumor cell survival under hypoxia. Int J Cancer 2006;118:1660-1669.

22 Kamer I, Sarig R, Zaltsman Y, et al. Proapoptotic BID is an ATM effector in the DNA-damage response. Cell 2005;122:593-603.

23 Zinkel SS, Hurov KE, Ong C, et al. A role for proapoptotic BID in the DNA-damage response. Cell 2005;122:579-591.

24 Zermati Y, Mouhamad S, Stergiou L, et al. Nonapoptotic role for Apaf-1 in the DNA damage checkpoint. Mol Cell 2007;28:624-637.

25 Wang Q, Gao F, May WS, et al. Bcl2 negatively regulates DNA double-strand-break repair through a nonhomologous end-joining pathway. Mol Cell 2008;29:488-498.

26 Smirnova E, Griparic L, Shurland DL, et al. Dynamin-related protein Drp1 is required for mitochondrial division in mammalian cells. Mol Biol Cell 2001;12:2245-2256.

27 Breckenridge DG, Stojanovic M, Marcellus RC, et al. Caspase cleavage product of BAP31 induces mitochon- 
drial fission through endoplasmic reticulum calcium signals, enhancing cytochrome $c$ release to the cytosol. J Cell Biol 2003;160:1115-1127.

28 Varadi A, Johnson-Cadwell LI, Cirulli V, et al. Cytoplasmic dynein regulates the subcellular distribution of mitochondria by controlling the recruitment of the fission factor dynamin-related protein-1. J Cell Sci 2004;117:4389-4400.

29 Sugasawa K, Ng JM, Masutani C, et al. Two human homologs of Rad23 are functionally interchangeable in complex formation and stimulation of XPC repair activity. Mol Cell Biol 1997;17:6924-6931.

30 Rockett JC, Patrizio P, Schmid JE, et al. Gene expression patterns associated with infertility in humans and rodent models. Mutat Res 2004;549:225-240.

31 Withers-Ward ES, Jowett JB, Stewart SA, et al. Human immunodeficiency virus type $1 \mathrm{Vpr}$ interacts with hHR23A, a cellular protein implicated in nucleotide excision DNA repair. J Virol 1997;71:9732-9742.

32 Brignone C, Bradley KE, Kisselev AF, et al. A postubiquitination role for MDM2 and hHR23A in the p53 degradation pathway. Oncogene 2004;23:4121-4129.
33 Wsierska-Gadek J, Horky M. How the nucleolar sequestration of p53 protein or its interplayers contributes to its (re)-activation. Ann NY Acad Sci 2003;1010:266-272.

34 Chook YM, Bloble G. Karyopherins and nuclear import. Curr Opin Struct Biol 2001;11:703-715.

35 Conradt B. Cell biology: mitochondria shape up. Nature 2006;443:646-647.

36 Boutros R, Lobjois V, Ducommun B. CDC25 phosphatases in cancer cells: key players? Good targets? Nat Rev Cancer 2007;7:495-507.

37 van Vugt MA, Medema RH. Getting in and out of mitosis with Polo-like kinase-1. Oncogene 2005;24:2844-2859.

38 Lee M, Hwang JT, Lee Hj, et al. AMP-activated protein kinase activity is critical for hypoxia-inducible factor-1 transcriptional activity and its target gene expression under hypoxic conditions in DU145 cells. J Biol Chem 2003;278:39653-39661.

39 Hardie DG. The AMP-activated protein kinase pathway-new players upstream and downstream. J Cell Sci 2004;117:5479-5487.

Supplementary Information accompanies the paper on Modern Pathology website (http://www.nature.com/ modpathol) 